\title{
Taking Responsibility for Negligence and Non-negligence
}

\section{Garrath Williams ${ }^{1}[0$}

Published online: 21 September 2019

(c) The Author(s) 2019

\begin{abstract}
Negligence reminds us that we often do and cause things unawares, occasionally with grave results. Given the lack of foresight and intention, some authors argue that people should not be judged culpable for negligence. This paper offers a contrasting view. It argues that gaining control (over our agency, over a risky world) is itself a fundamental responsibility, with both collective and individual elements. The paper underlines both sides, focussing on how they relate as we ascribe responsibility or culpability. Following the introduction, Section 2 ("Culpability and Control: The Negligence Sceptics") argues that conscious awareness is neither necessary nor sufficient for control. Control is not a property of deliberate choice, so much as a practical achievement. Section 3 ("Non-negligence as a Shared Task") stresses the collective aspects of non-negligence: creating knowledge about risks, structuring environments to guard against them, and developing standards of care. Failings in the collective task, rather than lack of individual control, mean it can often be unfair to pin culpability on a single individual. Section 4 ("Culpability for Negligence Revisited") suggests that a basic duty of a responsible person is to acknowledge the ways in which we may do more or less than we mean to, often in ways that create risks. It then sketches an approach to culpability as part of a collective exercise: as we take responsibility for standards of care, and for our own and others' agency.
\end{abstract}

Keywords Negligence $\cdot$ Culpability $\cdot$ Responsibility $\cdot$ Blame cultures $\cdot$ Scepticism

\section{Introduction}

Negligence is neither deliberate nor witting. This simple definitional point reflects deeper truths about our agency. We are finite: we cannot foresee all risks and we cannot attend to everything at once. We are fallible and sometimes fail to attend to important matters. However inadvertently, we sometimes contribute to harms that

Garrath Williams

g.d.williams@lancaster.ac.uk

1 Department of Politics, Philosophy and Religion, Lancaster University, Lancaster LA1 4YL, UK 
might have been averted. According to some authors, this implies that people are not culpable for negligent actions: for shorthand, negligence scepticism.

In this article, I explore the normative structure of negligence and non-negligence, using this scepticism as a foil. Section 2 discusses the negligence sceptics and their reliance on an intuitive connection between (criminal) responsibility and 'control' in the sense of self-aware, deliberate action. Framed in these terms, liability for negligence does look puzzling. But I suggest that this notion of control is misconceived. Focussing on conscious awareness, the sceptics side-line a more substantial sense of control: that exercised by the competent person who acts on her own account. It makes better sense to conceive of control as an achievement: the ability to do what we mean to do and to abide by standards we acknowledge. That includes the ability to go about daily activities without imposing undue risks - and without constant, exhausting, even counter-productive vigilance.

In Section 3, I emphasise the collective efforts that make this individual control possible. We take care; we take responsibility for non-negligence. To pre-empt risks requires much more than each obeying some Thou shalt not-s. Thou shalt take care points to complex demands within a collective endeavour that forestalls and mitigates risks. As such, negligence is different to other wrongs. Although it can be just as damaging, a wider range of excusing factors may lead someone astray. Like other forms of philosophical scepticism, negligence scepticism distracts from more specific reasons for caution. Apart from problems of individual 'control,' we should ask how fair and helpful it is to pin fault on one person, when others might also have done more. This shows why negligence is rarely a criminal matter, however one understands the basis for such culpability.

In Section 4, I sketch an approach to responsibility for negligence that takes account of the limits of individual control, and emphasises the collective project of taking responsibility for non-negligence. I will not try to adjudicate when legal penalties should apply, but I will emphasise individual duties to take responsibility, and how these may anchor ascriptions of moral and legal culpability. We can see norms of culpability as part of a collective exercise in setting and upholding authoritative standards of care. We ask and, especially in the worst cases, demand that those who have gone wrong play their part. We hold responsible as part of taking responsibility: for standards of care, for our own and one another's agency.

\section{Culpability and Control: The Negligence Sceptics}

Since negligence involves no specific intent or awareness or choice, it easily generates puzzles about culpability. The negligent person didn't mean to do any harm; she didn't realise she was exposing anyone to risk. While one instance of negligence may go unnoticed and do no harm, another may cause enormous damage and suffering. ${ }^{1}$ If it's unfair to hold someone responsible for something she didn't mean to

\footnotetext{
1 Parallel worries about 'moral (bad) luck' also arise for the outcomes of deliberate conduct. But they may seem especially weighty in the case of negligence, where most failures prove harmless and just a few prove disastrous — c.f. Waldron's contrast between 'Fate' and 'Fortune' (1995: 387). Another worry
} 
do or couldn't help doing, isn't it also unfair to attach greater liability to one person than another, supposing the facts about their agency are equivalent? We can frame these worries in terms of control: negligent actors lack control, both in the sense that many chance, unknown factors may intervene, and in the sense that they don't even know (or at any rate, take awareness) that their actions or omissions expose others to risks.

Larry Alexander and Kimberley Ferzan put the point bluntly: 'Culpability entails control, and the negligent actor does not have this requisite control' (2009: 85). In their example, self-absorbed, social-climbing parents greet and mingle with their dinner party guests. They forget about their small child, whom they left in a running bath. The infant drowns. The parents fail any reasonable test of care, including Alexander and Ferzan's own: they demonstrate 'insufficient concern... for the legally protected interests of others.' ${ }^{2}$ But culpability requires an 'occurrent mental state' 3 - as in recklessness, for example, when someone notices a risk but decides to go ahead regardless. Say Alexander and Ferzan: the forgetful parents are negligent but not culpable.

Michael Moore and Heidi Hurd also offer a sceptical treatment of negligence. They conclude that negligence is simply a rag-bag: a 'residual category of culpability sweeping up a diverse set of situations having little in common with one another, save that they do not fully meet all of the requirements of the higher levels of culpability' (2011: 192). Like Alexander and Ferzan, their main target is criminal culpability, but Hurd (2014) also makes similar arguments regarding fault-based tort liability. ${ }^{4}$ Again, they notice that various defects may be revealed by negligence. Hence Moore and Hurd's title, brave for even the most virtuous author: '...the Awkward, the Stupid, the Weak, and the Selfish.' Informally, we might blame negligent conduct if it reveals vices-'aretaic appraisal,' as they put it. But bad character does not justify the law's 'deontic appraisal' that someone has acted culpably. ${ }^{5}$ It is, they say,

\footnotetext{
Footnote 1 (continued)

about fairness arises insofar as persons who lack normal capacities (for instance, to foresee risks) may be found guilty of negligence, a point I do not engage with here (see Keating 2017: 24f).

2 (2009: 24.) Alexander and Ferzan later claim: 'We stipulate that Sam and Ruth act justifiably' in leaving the baby (2012: 284). Actually, they say only that the parents leave the child 'believing correctly... they will have plenty of time to return to the child after they have welcomed the guests' (2009: 77). But the correctness of this belief is beside the point. Even if true, leaving the baby is unjustifiable-not least because of obvious risk of distraction once the baby is out of sight.

3 As opposed to 'a character trait or disposition' (Alexander 2000: 931). 'Occurrent' is already a strange word for a control theorist to use: I do not control whether something 'occurs' to me (c.f. Alexander and Ferzan 2009: 153 n. 76). As Alexander notes, this raises a difficult question as to what level of conscious awareness counts, opining that 'low-level consciousness of risk' suffices (2000: 954 n. 62). By contrast, on the picture I will sketch the combination of active (e.g., 'control') and passive (e.g., 'occur') language is quite natural. This picture draws on Smith (2005) and Hieronymi (2014). Sher (2009) effectively attacks views of responsibility that hinge on the 'searchlight of an agent's consciousness.'

${ }^{4}$ King (2009) applies similar arguments to negligence as a matter of moral responsibility.

5 Moore and Hurd (2011: 169f), c.f. Alexander and Ferzan (2009: 16f). I set aside an important difference between these authors concerning the culpability of morally mistaken actors. Alexander and Ferzan hold that wrongdoing can be culpable when someone does not see his act as wrong (2009: 153). In this case, control is wholly dubious as a criterion of culpability. Of course, such a person exercises control in the sense that he acts in line with his moral judgment. But in judging his action culpable, law reas-
} 
'the flawless use of our practical rationality that makes us blameworthy [or rather: legally culpable_-GW] for intentional/reckless actions (when we aim at or tolerate known evils)' (2011: 166).

\subsection{Wrongdoing as Lack of Control}

Setting aside the question of how often people self-consciously see themselves as acting wrongly, I want to challenge the notion of control that these authors invoke. In doing so, my wider aim will be to suggest that control is not an a priori feature of our mental or volitional life, that obtains whenever a sane person makes self-aware decisions. As such, it does not provide a straightforward starting point for ideas of culpability or responsibility. Control is a fallible, practical achievement. In a risky, uncertain world, its lack can be a serious fault.

Note, first, how odd Moore and Hurd's phrasing is. How can aiming at or tolerating what one knows to be evil represent a 'flawless use of our practical rationality'? We can take their point that negligence often involves the 'flawed use of these same practically rational faculties' (2011: 169)—-thus the 'four sources of inadvertence' of their brave title: clumsiness, stupidity, weakness, selfishness. But to hold that there is no flaw in deliberately flouting standards of right and wrong is reckless indeed. Whatever else practical rationality may be, it is the ability to act in the light of our judgments of right and wrong. ${ }^{6}$

This undermines the notion of control that they see as necessary for culpability. How are we to make sense of an actor who knowingly departs from standards of right and wrong? I see just two ways. ${ }^{7}$ On the one hand, the actor may make a deliberate decision to act in line with her own interests, desires or impulses, rather than in line with moral requirements. Her choice is selfish and she knows it to be so. As Michael Zimmerman puts it, 'Every chain of culpability is such that at its origin lies an item of behavior for which the agent is directly culpable and which the agent believed, at the time at which the behavior occurred, to be overall morally wrong'

\footnotetext{
Footnote 5 (continued)

serts its control over the criminal. Alexander and Ferzan (2018) give this point more attention, noting (but not, I think, resolving) the difficulty for control theorists: 'actors have no control at the moment they act over how the balance of reasons appears to them' (104). Moore and Hurd claim that culpability rests on 'wrongdoing in the mind of the actor' (2011: 150), implying that the morally deluded criminal is legally off the hook. However, both are of two minds on this point. Elsewhere, Moore claims, 'in order to be most culpable[,] one need only desire to do a certain act A for its own sake, and it must also be the case that morality makes A wrong to do' (1997: 412f). Hurd (2014) also takes a more nuanced view: a person who 'acts culpably... need not draw the conclusion that it is wrongful, but she does have to have a description of the act in her mind that embodies the characteristics of the act that make it objectively wrongful' (390). Both quotes again raise the embarrassing question for control-spells-culpability theorists: how central can conscious control be, if we may ascribe culpability to someone who fails to see that she does wrong?

6 The 'our' in this sentence is a weasel word: it leaves open the relevant 'we,' and hence ducks problems of moral error and disagreement (previous note). This does not affect the basic point: the wrongdoer who both endorses and breaches a standard should be no one's model of flawless control.

7 Psychologically, one might see these as extremes on a continuum, with all sorts of bad faith and evasion in between. This would only reinforce the problems about control that I raise.
} 
(2009: 257). This is the strength of Lucifer's rebellion: 'evil be thou my good,' flawless at least in its wilfulness. On the other hand, the actor might be weak willed. She knows the good and in some sense wants to do it. But she gives into her baser impulses. This is a possibility that Gideon Rosen expresses, with useful boldness: 'the only possible locus of original responsibility is an akratic act. In weakness begins responsibility. Our first sin must be a knowing sin-a sin done in full knowledge of every pertinent fact or principle' (2004: 307). ${ }^{8}$ This is the weakness of Eve, as she gives into temptation.

Neither, I suggest, seems much like a model of control. For the weak-willed actor, the difficulty hardly needs spelling out. ${ }^{9}$ Weakness of will is a paradigm failing of control. When I cannot bring myself to do my duty, I learn the limits of my selfcontrol. For the more wilful actor, the point is a bit more complicated. In terms that the advocates of control-spells-culpability urge upon us, we might ask: why did she not exercise her capacity to act rightly? But then the difficulty is to see what this capacity amounts to. ${ }^{10}$ Everyone can admit that the actor 'could' have acted rightly if she had faced fewer incentives to act wrongly. But what does it mean to say that she could have acted rightly in that situation with the same incentives? Of course, we can exhort someone to think of herself as able to do as she ought. ${ }^{11}$ If she values our good opinion or fears our reprisals, this may bolster her future readiness to act differently. The actor herself might even claim: I could have done better. But it is hard to say what these words amount to, unless (again) an exhortation to her future self or just an admission that she accepts our resentment or penalties. In other words, there might be consequentialist reasons to refer to a capacity to do better: by thinking of one another as able to do better, we encourage one another to become better. ${ }^{12}$ But all our sceptical authors advocate a desert-based notion of culpability: possible good effects are not enough to justify penalising someone, especially the special opprobrium of criminal conviction. So the reference to capacity takes us no

\footnotetext{
${ }^{8}$ Alexander and Ferzan cite both Zimmerman and Rosen as authorities for their view that 'one is culpable only for acts over which one has control' (2009: 79).

${ }^{9}$ If I read them right, Moore and Hurd would agree (2011: 168), c.f. Hurd (2014: 399).

${ }^{10}$ Moore and Hurd reject Hart's idea that negligence may show the 'culpability of unexercised capacity': the negligent person could have realised the risks he was running (2011: 162ff). But to interpret deliberate wrongs as instances of control is also to invoke an 'unexercised capacity,' viz., to choose rightly. Although Moore and Hurd register the point (151), their response makes control merely hypothetical: "because choice makes one culpable... one can give sense to there being a capacity to have done otherwise in terms of the implicit conditional, "if one had chosen to do otherwise" (164; see also Moore 1997: 540-546).

${ }^{11}$ McGeer and Pettit (2015) stress this exhortatory aspect. When we encounter someone's selfishness (say), why do we not merely register regret or disappointment? In the first place, McGeer and Pettit see 'could have' as an exhortation to the person: a reminder that she ought to do better which is meant to bolster her capacity to do better. A retributive element arises from our being 'invested in having a certain effect on performance' (179). Our anger can be construed as a penalty on the logic of a practice that issues and upholds authoritative norms: 'I blame you for [e.g.,] not having paid attention, insisting that you could have done otherwise. I impose on you the penalty that promised, by shared assumption, to attend any failure to abide by the injunction' (184). For a doubt about this point, see n. 48 .

${ }^{12}$ In addition to the previous reference, see McGeer (2019) and Vargas (2013, forthcoming). I briefly return to these forward-looking approaches in the last part of Sect. 4.
} 
further than the claim that we were hoping to justify: deliberate selfishness deserves an adverse response.

In both cases, then, self-seeking urges overwhelm someone's knowledge of right and wrong-wilfully or reluctantly, as the case may be. If someone acts against his own moral commitments, then we confront an incapacity, not a form of control. ${ }^{13} \mathrm{I}$ don't think we should doubt that clear-eyed selfishness or weak will can be culpable, although these problems surely call for a different account of culpability. But my initial claim is simpler. By this count, there is no special reason to worry about culpability for negligent acts. In each case, the actor knows, or claims to know, that he should take account of others' interests or rights — and then fails to do.

\subsection{Voluntariness and Control}

As Andrew Simester has noted (2000, 2013), by depicting control in terms of conscious choice, the sceptics neglect a more meaningful notion of control. This is our ability to act voluntarily, whether with or without conscious deliberation. A selfaware mental decision may involve a particular feeling of control, of different possibilities being 'up to me.' But we should resist the temptation to see self-aware choice as either guarantee or precondition of control.

On the one hand, conscious awareness does not suffice for control. ${ }^{14}$ We can always ask how far a person is 'in control' of her own thought processes. There's no scepticism in noting that things 'occur to' or 'strike' us, or that they may fail to so do: this belongs to the nature of all mental activities (Fingarette 2004). We can deliberate about options, but not about whether something will occur to us as an option. We can't know whether the relevant pros and cons will strike us correctly. Deliberation can be dithering or self-deception-an unacknowledged effort to evade realities one does not want to see or duties one does not wish to fulfil. Not that deliberation need be idle. ${ }^{15}$ But a person can only make up her mind using a mind that has already, in countless respects, been made.

On the other hand, conscious awareness is not needed for control. No intelligent activity could get off the ground if we could not rely on the unreflective functioning of many other skills-including an enormous amount of knowledge that we take account of without explicit notice. ${ }^{16}$ Skilled activity requires this immediacy

\footnotetext{
13 Compare how odd it would be to speak of a 'capacity' to make mistakes in mathematics or speaking a language. To say we 'can' make mistakes is just to say that our ability is partial or fallible, not to ascribe some curious additional ability.

14 Duff (1990) focusses on this point. He argues (rightly, to my mind) that the sceptics are hostage to a false ('Dualist') philosophy of mind, that over-emphasises the role of 'occurrent mental states' and ignores how much of our knowledge and mental activity is not a matter of conscious awareness.

15 That view is sometimes attributed to Sartre, who liked to say that when we deliberate, les jeux sont faits: the game is up. But this is not to claim that deliberation is a charade, just that it is (necessarily) shaped by our existing projects and priorities (Webber 2009: 34).

16 Which is also to say: it is a fool's errand to seek an 'occurrent mental state, even in the form of 'low-level consciousness' (Alexander 2000: 954 n. 76) or 'preconscious' advertence (Moore and Hurd 2011: 153f), in order to ascribe beliefs, whether regarding a risk or anything else (c.f. Duff 1990). Stark (2016) also holds that negligence can be culpable, although there should be a high bar for criminalisa-
} 
and may be hindered by deliberation: compare the fluent speaker or ready wit with someone effortfully groping for the right words. ${ }^{17}$ Often, conscious effort indicates inexperience or the limits of our abilities - a sign, perhaps, that we should seek help or step back from the activity. Again, this is not to say that deliberation or conscious awareness are idle. It is just to underline how profoundly our agency rests on tacit knowledge, settled policies, carefully cultivated habits.

More broadly: unless I am under grave pressure, such as duress or derangement, what I do is up to me anyhow. Deliberate or spontaneous, a voluntary deed is an exercise of my agency. I act on my own sense of what is true or good or worthwhile. In doing so, I rely on a range of active powers - for example, my capacities for sensitivity and responsiveness, and my practical competencies in translating priorities into action.

Admittedly, this control is conditioned and conditional: limited by a world that I do not control and by my limited abilities to appreciate it. Nothing guarantees that I will calculate or judge correctly; I may forget and omit and neglect matters that are important by my own lights, never mind other people's. But this control has substance because it involves the power to effect changes in the world. Decisions are impotent until I act upon them, at which point I come up against all the risks (and rewards!) of dealing with a world beyond my mind. ${ }^{18}$ We may be more or less optimistic as to how far people can really know and fully understand what they do, in its social and moral significance as well as its material implications. But such control represents an achievement and not a default-not even if we artificially confine agency to an adult's self-conscious mental decisions.

Seen in this way, culpability for negligence poses no special puzzle. This is not to deny genuine differences. In case of self-aware wrongs, someone doesn't abide by standards she acknowledges, even as she acts. ${ }^{19}$ In case of negligence, by contrast, the actor is likely to become aware of her lack of control only after the (f)act, when some unintended, unforeseen risk materialises. Hopefully, she will regret this, as the person who willingly does wrong may not. ${ }^{20}$ As I will stress, valid excuses are more likely to apply to negligence than other forms of wrongdoing. But it cannot be its own excuse, simply as such, that one fails to notice or remember risks that one is committed to avoiding - for example, the plain risk that a baby may drown in

\footnotetext{
Footnote 16 (continued)

tion (Chap. 8). His argument centres on a more sophisticated analysis of belief, as based on 'dispositions towards thought and conduct' rather than conscious or introspected states (Chap. 4).

17 In other words, not only may spontaneous or habitual activity be thoroughly intelligent, rational and responsive; it may involve more control than deliberate attempts, especially where I am still developing the relevant skills and habits (Railton 2009).

18 Among other things, I may learn that my intention was not as clear or sensible or urgent as I took it to be. Ripstein (2008: 67f) makes a related argument that 'trying' seems infallible: I can't fail to try, even if success is in the lap of the gods. But this is because it is only a derivative notion, a shadow of the actual deed.

19 As noted [n. 5], I leave aside cases of moral or legal mistake: such an actor plainly cannot control herself on the same terms as those she will be judged and penalised by.

20 Duff (2019: Sect. 5) reminds us of Aristotle's category of the counter-voluntary, where a person does something without meaning to, yet is not pained by that fact.
} 
bathwater. $^{21}$ As I will stress in Sect. 4, anyone who feels appropriate moral concern must be committed to incorporating this into her agency (Simester 2000: 89). To care about others is to acknowledge a duty to take care of them-and not merely of whatever aspects of their wellbeing pass before one's conscious notice.

\section{Non-negligence as a Shared Task}

Negligence scepticism is a minority position. Most authors think a few forms of negligence merit criminal penalties-for example, some cases of careless driving or child neglect or medical malpractice. Apart from Hurd (2014), few doubt that negligence can be a civil wrong, although there is room for disagreement as to when liability should involve moral condemnation or a duty to compensate, or indeed, how far compensation should represent an individual duty. As noted, I am hardly the first to point out difficulties in the sceptics' theoretical arguments about control. My constructive claim is that these problems can point us to a better way of conceiving the relation between culpability and control. In particular, we may appreciate the collective dimensions of control, especially as they relate to risk, and the role that culpability ascriptions play in these collective endeavours.

The classic Thou shalt not-s of criminal law are simple to state and, most of the time, simple to follow. Our compliance is mostly inadvertent: a well-socialised person rarely wants to commit assault; she may be jealous of someone's possessions, but rarely thinks of stealing. Although I have been resisting the sceptics' tempting equation of advertence with control, there is no denying that breaches are likely to be advertent. ${ }^{22}$ By contrast, Thou shalt take care represents an indefinite and demanding standard. ${ }^{23}$ It bears on a whole range of essential and desirable activities: providing health care, bringing up children, driving. All sorts of factors are bound to lie outside my control and awareness: how can I gain some assurance that I will do what I mean to and avoid the worst risks? Some precepts are straightforward (for

\footnotetext{
21 As noted [n. 2], this is Alexander and Ferzan's own example. It is a bad one since the standard of care involved is very simple: Never leave a small child unwatched in water. By contrast, and to illustrate the point about excuses, consider cases where infants die when left in overheated cars. Weingarten points out that such deaths began to occur 'in the early 1990s, [after] car-safety experts declared that passenger-side front airbags could kill children, and they recommended that child seats be moved to the back of the car' (2009: 10). There are many reasons why a driver might forget a child in a special safety seat; water is inherently unsafe for small children.

22 To amplify the point: selfish and weak-willed wrongdoers remind us that wrestling with (or against) one's desires and impulses often spells loss of control. Amid decent social arrangements, conscious efforts of will are more like emergency measures, for unfortunate situations where many factors conspire to tempt and pressure us.

23 Above, I set aside another sceptical claim, that norms to avoid risk must be either impossibly demanding or merely arbitrary (Alexander 2000: 949, 952f). For effective criticisms, see Johnson (2010), Leipold (2010). Ripstein (2016: 102ff) emphasises the importance of framing matters in terms of 'ordinary carefulness' - in one sense platitudinous, in another an essential pointer to thoughtfully worked out expectations in complex environments.
} 
example: Don't leave an infant alone in water). But mostly, the relevant Thou shalt-s only point to complex, multifaceted tasks (for example: Take care of your child). ${ }^{24}$

Here I want to invoke a claim that Seana Shiffrin (2017) has well defended. Forestalling risks is primarily a collective task, and one of great moral importance: the harms can be as terrible as those wreaked by any but the most malicious, premeditated wrongs. ${ }^{25}$ Decent societies build and maintain infrastructures of non-negligence, including shared knowledge about risks and shared practices to prevent them. Framed in this way, the task is first of all collective: how can we take responsibility for non-negligence? Only against such a background can we sensibly identify what individuals should do and render those tasks manageable. I will suggest that holding people responsible for negligence is one way, though not the most important way, in which we take responsibility for non-negligence. ${ }^{26}$ Ascribing legal culpability, be it criminal or civil fault, is one way in which we hold responsible.

The word 'responsibility' and its cognates are used in many ways. To clarify: by taking responsibility, I mean someone's actively dealing with a matter of concern. You take responsibility for the broken vase when you buy a replacement; an organisation takes responsibility for standards of care by emphasising those standards and promoting conditions where employees can live up to them. A person may take responsibility regardless of whether she or someone else or no one was at fault. You might replace the vase because you broke it, or because you care about the owner without having any idea how the breakage came about. Likewise, an organisation may take responsibility even where no one has breached standards of care: ensuring employees are aware of those standards and empowered to fulfil them. In yet other cases, one actor may take responsibility when someone else is at fault. Holding responsible is one form this can take. When we hold someone responsible, we take (some) responsibility for setting things right. If I blame someone, for example, I take responsibility for adjudicating and upholding certain moral standards. A court takes responsibility for upholding rights or interests when it finds that someone has culpably transgressed them.

\subsection{Framing Negligent Conduct within an Infrastructure of Non-negligence}

I have emphasised that our agency is always, to some extent, 'out of control' (Sher 2009: Chap. 9). Our attention is scarce; our knowledge is limited and fallible.

\footnotetext{
${ }^{24}$ I will not develop the point, but a parallel issue applies to most moral commitments. One might say: we can be negligent with regard to these, and fail to keep track of their implications. We know we ought to be grateful-but don't take proper account of what someone has done for us or understand how we should conduct ourselves in response. Again, non-negligence is only partly served by conscious deliberation. What really matters is our tacit awareness, our experience of human relationships, and our sensitivity to others-including our ability to learn from their disappointment and rebukes.

25 In what follows, I will frame matters in terms of 'societies,' a vague term but one that unfortunately side-lines global and international dimensions of risk prevention. I thank Lisa Herzog for the valuable reminder that many serious forms of negligence (not to say recklessness) arise across borders and even, if we think of climate destabilisation, across generations.

26 Some related ideas are at work in Gardner (2017).
} 
However much care or self-control we muster, there is much that we cannot anticipate or attend to. This is a basic fact about our place in a material world. However skilled and knowledgeable we are, intentions do not materialise smoothly in results. It is a basic fact about our place in the social world, too. We live among others with their own wills and intentions, sensitivities and peccadilloes. However 'well adjusted' we are, we can't be in control, because other people are free beings who act and respond on their own account, not on ours.

This lack of control is, if you like, our natural condition. But it is not a brute fact. We mitigate it by all sorts of precautions: material and technological, cognitive and informational, social and organisational. We learn how to create reliable technologies, robust structures, clear instructions, safeguards and fail-safes, back-ups and fallbacks. Education about risks is an important part of growing up and continues throughout our lives - as news stories make us aware of new hazards, for instance. Enormous efforts go into organising people in non-negligent ways: for example, creating institutions that effectively pursue human goods and do not impose systematic risks on members or customers or strangers. Part of these activities is working out how individuals can contribute properly-for example, what it means for parents to take care in a complex, technological society, or nurses to show due care in organisational settings. We internalise these standards as we gain experience of different fields of activity. For especially risky fields, like driving or health care, we train and examine candidates, refusing licences to those who, for whatever reason, cannot manage all the relevant demands. This represents a massive collective effort- $\mathrm{a}$ social infrastructure of non-negligence.

One reward of this infrastructure is that each of us has fewer opportunities to pose risks to self and others. Another is that, even when we fall into those opportunities, severe harms only rarely come about. Yet another reward is that we need not pay constant attention to risks - a good job, given how scarce and selective our attention must be. By our social scaffolding of non-negligence, we have, by-and-large, already learned how to take account of various risks without active effort or awareness. We learn and teach one another what it is to do everyday activities well-meaning not just 'successfully in terms of one's immediate purposes' but 'with due caution for the manifold risks of an unpredictable, interconnected world.' For the well-socialised 'reasonable person,' non-negligence is relatively easy to maintain while pursuing other goals and initiatives.

I underline this point because how we frame success affects how we think about failure, and vice versa. The negligence sceptics tend to frame negligent acts as unwitting omissions - as if the paradigm of non-negligence were deliberate, selfconscious attention to risks. ${ }^{27}$ This is wrong. It is not true in theory, as regards the structure of human agency. All the time, almost all of our knowledge and moral commitments lie outside our awareness, even as they inform our activity. It is not true in practice, among our infrastructures of non-negligence. The everyday nonnegligent conduct of reasonable persons depends on a second nature: intelligent

${ }^{27}$ For a recent framing of negligence as mere, sheer absence, see Claire Finkelstein's contributions to Yankah (2018). 
skills, thoughtful emotions, careful habits that incorporate a whole range of demands into our agency. Of course, special or deliberate forms of attention are sometimes needed. But that just means that one important skill is the ability to notice when this is so.

Looked at in this way, negligent conduct is less a matter of omission and more a matter of doing some activity badly. ${ }^{28}$ Doing complex activities well-being a good parent, fulfilling a professional role, successfully Doing-It-Yourself-involves focus on a few things with background awareness of many others. What is remarkable is the degree of control that we often achieve in juggling so many demands, keeping many balls in the air, spinning many plates. ${ }^{29}$ Nonetheless, despite all collective precautions, we sometimes fail, and sometimes these failings have grave costs to self or others. To decide how we should respond to such failings, the negligence sceptics look for a deliberate exercise of will that would make someone culpable. (Or alternatively for underlying vices, that merit social rather than legal condemnation.) I suggest we can make better sense of things if we frame our responses differently: as attempts to take responsibility for non-negligence, by attending to instances of negligence. In a slogan: holding responsible is taking responsibility. But also: just one part of it.

\subsection{Responding to Negligence: Cautions about Culpability}

Before fleshing out this thought, let me underline some practical worries about emphasising culpability. As I hinted at the start, philosophical scepticism deserves a sceptical eye. A priori doubts easily divert attention from hard-won practical experience. Two practical lessons strike me as key. It may not be fair to focus on individual 'culprits,' and it may not be useful. ${ }^{30}$

In my view, the main worries about fairness relate not to the idea that negligent persons lack control, but rather to the collective dimensions of non-negligence. ${ }^{31}$ In any collective project, questions arise about the fairness of demands placed on individuals, and individualised (and especially punitive) judgments about failure. When serious risks eventuate, it is rarely the case that everyone else has done their share and just one person has failed in hers. Without necessarily being able to point

\footnotetext{
${ }^{28}$ I take this point from Helmreich: "misperformance or "failed" performance presupposes—rather than competence, per se-some kind of task or project one is engaged in... [O]ne is misperforming because one is... performing in the first place... [T] he performance of setting out to avoid harming others, the task of keeping one's activities safe for those in one's path, is presumably an ongoing project of all but the truly reckless or malicious...' (2018: 340).

29 Whatever we say about the institutional faults that conduce to acts and habits of negligence, note that we expect responsible adults, especially professionals, to take awareness of institutional imperfections. These are inevitable amid the many different pressures to which organisations and their members are subject; it would be negligent, if not reckless, for anyone to suppose otherwise.

30 Baron (2019) argues that some well-known criminal convictions for negligence are highly problematic, but that these do not impugn the more general claim that negligence is sometimes a criminal matter.

31 A related worry arises from the disproportion between act and outcome inherent in the idea of risk: adverse outcomes obviously draw attention, while harmless breaches are liable to go undetected. Again, this may temper our readiness to judge harshly, without casting doubt on culpability itself.
} 
the finger at any other particular culprit or problem, we might judge that too much was asked of a single person. Even if the driver ought to have pressed the other button, should the machine have been designed so that it could cut out so disastrously? Could we really expect an overstretched, underslept trainee medic to notice that risk? ${ }^{32}$

I mention the health care context because the challenges of improving safety here are well known, ${ }^{33}$ and because the 'blame culture' of many medical organisations is widely recognised as unfair and ineffective. Just occasionally, negligent individuals face punishing treatment-if not (at the end of the day) specific penalties, then at least enormously stressful procedures, when it can feel like the whole weight of an organisation smothers one's life and destroys all peace of mind. ${ }^{34}$ More often, those involved manage to hide the loose threads-fudging the record, obfuscating events, defending themselves against what is meant to be sensible investigation but might just as well prove a witch hunt. Similarly, the organisations they belong to often act defensively and deceptively_as likely to add insult to the victim's original injury as to deal with the alleged culprit or institutional failings. Instead of 'trial and error,' we have systematic errors and occasional trials of individuals; patients go the hard way and organisations fail to learn from it. ${ }^{35}$ That is a form of collective negligence, and one face of it is an unfair and unconstructive preoccupation with individual liability.

As many of these scenarios also highlight, people may act without due care, not because they don't care, but because they lack skills or face acute pressure. As such, moralising responses may be over-hasty, counter-productive and even vindictive. Especially when we think about professional conduct and institutional responses (employers or accreditation bodies, and sometimes the courts), questions about proficiency and suitability for a given role take centre-stage. This is not to say that concerns about people's moral commitments disappear, as a literal interpretation of the phrase 'no-blame culture' might suggest. Concern for others implies duties to cultivate competences, and to avoid activities or seek support where one lacks competence. But that is also to acknowledge that the path from concern to competence_-and especially to the ability to handle very demanding situations — is

\footnotetext{
32 Thus the high-profile UK case of Hadiza Bawa-Garba (Cohen 2018). Compare also the problematic English case of $R v$ Adomako [1994] 3 WLR 288, where an anaesthetist's conviction for gross negligence manslaughter was upheld by the Law Lords. As one of his prosecutors later commented: 'There must be a failure in the system... which allows a man so poorly qualified... to preside over operations... when his expertise was not very good and his tiredness was extreme. The Hospital [involved] knew he was working 5 days a week at other hospitals... and they summoned him on duty after he had had about 4 hours sleep' (Curnow 1996: 191).

33 Often by contrast with the airline industry-remarkably safe, if one ignores its contributions to climate destabilisation. A large literature attempts to draw lessons across the two domains. (See Reason 2000; Pronovost et al. 2009.) On the problem of combining responses to individuals with cultural and organisational measures, see Dekker (2012).

34 'The process is the punishment' [in the phrase made famous by Feeley (1979)] and may be unfair in all sorts of ways.

35 On difficulties in improving health care safety, see Dixon-Woods and Pronovost (2016), Provera et al. (2010).
} 
not straightforward. Alexander and Ferzan's stupidly self-absorbed parents ${ }^{36}$ are a world away from struggling, stigmatised parents whose child dies for want of medical care, ${ }^{37}$ or loving parents whose infant dies when left in an overheated car. Both moral and legal judgment can recognise those differences. ${ }^{38}$

Not least, fault-based responses are unhelpful in addressing loss and injury. Negligence matters precisely because someone is liable to suffer. Legal proceedings impose further burdens on victims. If their claims are upheld, this only comes long months or years after the horse has bolted, and negligent individuals are rarely in a position to pay large damages. Dealing with suffering and injury and loss means emergency services, schemes for insurance or statutory compensation, long-term support for those who have suffered long-term disablement. Of course, most of these things are not specific to victims of negligence, in the normal legal sense of persons who can point to a specific individual who failed to take care. But that is quite right. This is not just because of the general principle that people who experience serious harms and losses deserve help. It also follows from the fact that, when serious harms eventuate amid the dense physical and normative fabric of modern life, there was either some form of negligence or some acceptance of risk. There will be much room for conflicting views as to whether there was organisational or political (if not individual) negligence, or which risks should be accepted (for example, as the price of various freedoms). In the meantime, someone must deal with the loss or injury. Fairness demands that it not just be the victim. ${ }^{39}$

From the perspective of the victims, we should also remember that what infuriates people most is generally not a lack of punitive measures. Instead, it is the failure to acknowledge and learn from the misfortune they have suffered. ${ }^{40}$ Again and again, victims and their loved ones say that they want to know that some preventable misfortune won't happen to others. The first condition for such learning is honest recognition of how things went wrong-not the denialism and witch-hunting and victim-blaming of blame-culture organisations. Compensation may make loss and injury bearable (sometimes imperative if the victim is to lead any sort of fulfilling life; sometimes impossible when we think of the worst harms). But the only thing that can make loss and injury meaningful are real steps to prevent their recurrence. This means that those involved, those responsible in the widest sense, must be prepared to take responsibility by facing the facts of the case and drawing the relevant lessons. Usually, these go beyond any single person's fault.

\footnotetext{
36 Baron (forthcoming) stresses just how senselessly the parents behave in this vignette.

37 State $v$ Williams, 484 P. 2d 1167 (Wash. App. 1971). I concur with Baron's (2019) critical discussion of this judgment.

38 To make such distinctions, we do not need to see law as punishing bad character, nor to see informal responses as condemnations of vice (see text at n. 5). As Simester stresses, law does not lay down intricate conditions for character or intent, but it expects courts to take account of specific persons and situations, with regard to fundamental values of mutual respect and concern (2013: 196f). To speak of mens rea is to refer, not just to specific mental states, but to the mindedness of the conduct (Baron 2019). As stressed in Sect. 2, the idea of a mind made in the moment makes no sense: we deliberate, or act impulsively, using the mind we already have.

39 This may be an argument for no-fault compensation schemes: Enoch (2014).

40 Perhaps I have the health care context too much in mind, but I suspect the point generalises.
} 


\section{Culpability for Negligence Revisited}

Pinning blame may be unfair or unhelpful or both. This suggests reasons for caution, but not for blanket scepticism about culpability. In daily life, we generally hold that the careless person should pay for the breakages he causes. Frank understanding of what went wrong sometimes shows a person falling below reasonable standards of care, even after other people and organisations have done their parts. Occasionally, someone's negligence seems frankly criminal, in the colloquial sense at least. Victims may seek punitive responses, not just acknowledgement and learning of lessons. Not least, culprits may feel profound remorse or seek to make amends. In doing some everyday activity badly, the careless person has failed to do his part in the collective endeavour of non-negligence. I propose to locate judgments of culpability in terms of this failing, and as part of the same collective endeavour. As noted, such responses sometimes fall into scapegoating and vengefulness: there is no guarantee that we will exercise proper care. Still, done well, we can see them as part of our care for the normative aspects of non-negligence-that is, promulgating and upholding standards for individual conduct, alongside all collective aspects.

Before going further, I should note strict limits to my discussion. The proper penalties for different wrongs form a large and troubling theme, inseparable from even larger questions about state authority, justice and freedom. Here I simply accept the view that grave wrongs typically merit coercive responses. In another sense, my comments will be broad. Having suggested caution with regard to criminal and civil penalties, my quarry will be a notion of culpability that bears on informal and organisational responses as well as (in the more glaring cases) legal ones. ${ }^{41} \mathrm{My}$ focus will be on the legitimacy of regarding the negligent actor as a culprit. I first consider a person's own duty to condemn her negligent conduct. Then I offer some more tentative ideas as to how holding responsible - the ways in which we act on judgments of culpability-represents a form of joint action, with interesting parallels to the collective activities involved in non-negligence. We tend to think of culpability in punitive terms, and its negative aspects are undeniable. But we can also frame it in terms of care: taking care of shared norms, taking responsibility for our own and others' agency.

\subsection{Excuses for Negligence: Royal Road or Primrose Path?}

As the sceptics stress, the negligent person can truthfully say I didn't mean to. That beats meant to, but it still means didn't take account of. An adult was exercising her right to undertake a risky activity, or even a specific authority-for example, to prescribe medicines or manage investments. Didn't mean to is true, but not the whole

\footnotetext{
41 Although I would not offer this as a general criterion, for negligence it seems a reasonable approximation to think in terms of more or less blatant, dangerous infringements. Criminal law specifies some bare minimums; tort law and organisational requirements are more demanding; professional standards may be stringent. Everyday morality may be both sharper (for example, the conscience of those with special obligations to the especially vulnerable) and more forgiving (for example, of those already riven by remorse).
} 
truth. It does not alter did it badly — that broader understanding of conduct neglected by the sceptics' framing.

Moore has described excuses as 'the royal road to theories of responsibility' (1997: 548). Without commending such a grand claim, I think it is revealing to consider the blunt, blanket excuse granted by the sceptics' conscious-control-asculpability logic. Imagine someone who said I just didn't think of that risk when I acted, as if that settled the matter. As stressed in Sect. 2, the self-aware wrongdoer might offer a parallel out-of-control plea: I knew I shouldn't but I couldn't resist; my desires or impulses determined my conduct, rather than my moral beliefs. Such pleas do not always lack force. Provocation is sometimes a partial defence; to steal food in the face of starvation may be no crime at all. Likewise, I have noted many reasons why a reasonable person might not, on occasion, show due care. Still, these are exceptions to a stricter demand-for self-control, not mere words nor bare intention.

Some aspects of everyday morality can also make this hard to see. Many of our demands concern underlying attitudes, and the intentions and wishes that mostly correspond to these. We gauge attitudes by patterns of sensitivity and interaction; mutual regard enables us to overcome occasional lapses (tactlessness, ingratitude, inconsiderateness, and so on) without much trouble. ${ }^{42}$ Relatedly, some moral demands concern ideals which human beings will never fully measure up to. In such cases, doing your best or even trying might be all that anyone can ask. ${ }^{43}$ For negligence, the issue is further complicated by the fact that perfect safety is an ideal beyond human power, and by the dismaying contingency of its harms.

But to note this contingency is also to emphasise the stakes. Unlike slights to dignity or disruption of relationships, material harms have a brutal irrevocability, especially where they touch the body itself. Again, note the feebleness of the corresponding excuse, or attempted mitigation: such conduct wouldn't usually have caused such harm. Hegel quoted an old proverb: 'A thrown stone belongs to the devil. ${ }^{44}$ Sadly, this applies to stones thoughtlessly left in the wrong place, and the whole gamut of negligent conduct. For the careless actor to plead wouldn't usually is to disparage the relevant standard of care, which matters precisely because of what might unusually happen. ${ }^{45}$ Wouldn't usually can do honest service only alongside it did ${ }^{46}$; didn't mean to is honest only alongside I did-that is, I did some activity badly, failing to take the care that we reasonably demand of one another. Next to our adult powers to undertake risky activities, not to mention the certain fact that the victim 'didn't mean' to suffer harm, didn't realise and wouldn't usually are childish things. Neither

\footnotetext{
${ }^{42}$ Note that even here, I forgot! (etc.) is no complete excuse. I didn't mean to, but you may reasonably expect some renewed manifestation of the care I failed to show.

43 Theoretically, things are complicated by the phrase, 'ought implies can.' But both 'ought' and 'can' lack single or simple meanings, so I think this slogan muddies rather than clarifies. On 'ought,' see Martin (2009); on 'can,' see Williams (2017).

44 'Der Stein, der aus der Hand geworfen wird, ist des Teufels,' Philosophy of Right, Sect. 119A.

45 Again, wouldn't usually can be an honest defence-where a person has taken proper care.

46 Or alternatively - for example in case of near-misses-it might have, meaning honest acknowledgement of what is at stake.
} 
morally nor theoretically do they constitute a plausible line between a responsible adult and unfortunate happenstance.

Although their standards and responses differ, both law and morality rightly say: Thou shalt take care. They do not say: Take all the care that is humanly possible; neither do they say: Take care insofar as it occurs to thee to do so. These standards acknowledge people's varying priorities and capacities and burdens-factors that make it unfair and unrealistic, even counter-productive, to insist on the highest standards of risk avoidance. (Or, indeed, on other ideals.) They define and demand good enough levels of responsiveness to the world, and especially to others' bodies and welfare: be a good enough parent, or doctor, or driver. ${ }^{47}$ Modest in one sense, 'reasonable care' is stringent in another. It demands actual care: conduct, not only attitude or effort.

Didn't realise, then, cannot operate as a general excuse, any more than couldn't resist. To treat it as such is to undermine the very idea of responsible agency, by denying the fundamental importance of the fact that we invariably do more and less and different than what we mean to or are aware of doing. (Just as we sometimes do not do what we believe we ought to do.) Often, attitudes and efforts matter more than specific performances or omissions or material effects. But some more-s and less-es and different-s really matter-above all, those that touch the safety and welfare of each person. One may say: we demand a basic attitude of each responsible person, that she not be too ready to plead mere intentions or the sheer contingencies of the world beyond her awareness. She must be willing to judge her conduct against standards of care that give us some protection against the worst contingencies. As Shiffrin puts it, a person thereby 'treat[s] her own agency as her responsibility, a responsibility to be exercised with sensitivity to the reality and equal importance of others' (2017: 214).

\subsection{Responses as a Form of Joint Action}

This is to interpret responsible agency as a duty, part of an overarching obligation to control ourselves by defensible standards. This may seem to beg a question: how to approach the responsibility of someone who does not acknowledge such a duty, if not in general then in some particulars? Think of all those variants on wouldn't usually and didn't realise: dangerous (even fatal) drivers who insist on their skill or care, the studied arrogance of a medic who shrugs you win some, you lose some, or just the everyday carelessness of someone who sees herself as charmingly insouciant.

Theories of responsibility often treat 'holding responsible' as simply doing something to someone. This tendency marks the sceptics' approach, not without grounds. Criminal penalties are inescapably coercive, like civil remedies. Coercion is the paradigm form of action that disregards another person's will. Nonetheless, I believe it is more illuminating to see such responses as attempts to do something with, not just to, the culprit. These attempts are anchored in the duty I have just referred to, to take

\footnotetext{
47 Compare Winnicott's (1964) wise defence of the 'ordinary good enough mother' against interfering, mistrustful professionals, not to mention a sexist culture always ready to blame her.
} 
responsibility for our agency. But they also reveal its collective dimensions. Both individually and through authoritative institutions, we take some responsibility for one another's agency. The metaphor quickly tangles, but as a starter one might say: we have duties to lead one another to water, though we cannot make someone drink. We lead to water as we educate and inculcate and debate moral standards, and legal ones too. We all stray, often unwittingly. Though we may be pained at the necessity, we must hope that others will lead us back. When someone is led but will not drink, judgments of culpability take on a special weight.

Our aim of acting with someone is obvious in the case of blame and other informal responses. Blame issues a sort of imperative-for example: Look how hurtful your thoughtlessness was! ${ }^{48}$ We thereby take some responsibility, not just for our own rights or standing, but also for how the other person understands herself and her conduct: we show ('lead') in the hope that she will see ('drink'). In taking this responsibility, we also have duties to acknowledge the other person's account of matters. Both sides, we hope, may come to a better understanding and take some shared responsibility. Now the metaphor becomes unwieldy: not one person leading and another drinking, but a more complex form of joint action. We also see this in case of apology and atoning. These practices invite the victim to extend forgiveness and the rest of us to make some peace with the culprit. Even where material harms are irreparable, such practices help mend relationships (Walker 2006) and (re)establish standards governing communities.

Formal measures obviously compel the culprit to heed accusation and judgment-hence the plausibility of framing desert and culpability as doing to. However, the culprit's attitude and responses will make important differences throughout. Civil and criminal proceedings force the accused to speak-and are bound to listen to him (Gardner 2003: 167f). Investigation, judgment and sentence will take account of his explanations, extenuations, contrition. It matters whether he will drink; less metaphorically, what sort of responsibility he is prepared to acknowledge. Organisational measures may be scarcely less coercive-for example, where someone's job or professional licence is at stake. Again, natural justice demands that such processes give a voice to the culprit, taking account of his words and record and attitude.

To frame culpability in terms of (hoped-for) participation is not to make it somehow voluntary: as if a guilty plea removed guilt, mea culpa cancelled tua culpa. It is just to emphasise that such cooperation is the most straightforward way to address worries about the authority and effectiveness of the standards concerned. To the extent that the culprit acknowledges his failing, he plays a part in reaffirming the authority of those standards and (re)incorporating them into his agency. ${ }^{49}$ By the same token, some refusals of responsibility frankly inculpate. Spoken as the whole

\footnotetext{
$\overline{48}$ With Hieronymi (2019), I believe discussions of blame are often distorted by an image of resentment and other reactive emotions as penalties_-something that we impose on other people in order to pain them ('guilt-tripping,' as Hieronymi puts it). But these reactions are not tools and we do not choose to feel them. Rather, they reflect how profoundly other people's actions and attitudes matter to us.

49 Contrast the double-bind facing those wrongly convicted, whose protestations of innocence count against (for example) early release.
} 
truth, didn't realise and wouldn't usually betray a lack of commitment to the relevant standards. (Compare a wrongdoer who pleads couldn't resist or really wanted to.) Informal responses reach a certain limit here: at most, we may withdraw trust or invite others to do so. Formal processes are more insistent. We sought to do something with the culprit: to honour a standard in the breach. Finding him unwilling, we may redouble our insistence. ${ }^{50}$

In trying to bring out what is at stake in ascriptions of culpability, these remarks may seem to bypass the sceptics' own concerns with desert, in favour of some consequentialist considerations. The idea that we take responsibility by holding responsible resonates with forward-looking approaches to responsibility: for example, the idea that we 'scaffold' one another's moral agency when we hold responsible. ${ }^{51}$ On the other side of things, there are many desert-based accounts of culpability beyond the negligence sceptics,' and I have left open broader questions regarding state coercion and penalties.

Between the lines, however, I have sought to loosen the hold of this familiar seesaw of philosophical sympathies, or at least to emphasise some aspects that matter either way. Alongside material structures (safer technologies and organisations, for example), non-negligence requires us to cooperate in working out standards of care for various activities. We collaborate, further, in upholding those standards. Prospectively, we make them effective as authoritative guides to conduct. This requires cooperation at many levels-especially so, because these standards defy codification and cannot operate just through effort of will or conscious notice; they must be worked out and learned, built into collective enterprises and incorporated into individual agency.

Retrospectively, we ascribe culpability to those who fail-at least if they were given a reasonable chance to succeed. We can also see this as part of a cooperative exercise in upholding these standards. Culpability provides little help in dealing with material consequences. 'Risk' already implies a disproportion between conduct and outcome; harms may be irrevocable or beyond the culprit's power to compensate; there may be no harm at all, just a horrified shudder at what might have been. Rather, culpability is a way of coming to grips with the normative consequences. There are inevitable doubts about someone's commitment to standards of care; we may doubt how seriously a particular organisation takes those standards; there is a wider question about how far those standards truly structure our lives together.

The culprit addresses these doubts by acknowledging did it badly, refusing to treat didn't realise or wouldn't usually as the whole truth. She thereby affirms the authority of these standards and her concern for the persons they safeguard. Depending on

\footnotetext{
50 Mason's (2019: Chap. 8) approach to 'ambiguous agency' (including much negligence) also stresses the reasons we have to take responsibility for failings, above all our concern for others. What I want to add is that failure to take responsibility may aggravate and even inculpate: it gives others (not least, legal institutions) special reasons to insist on culpability.

51 Thus Vargas (2013, forthcoming), McGeer and Pettit (2015) and McGeer (2019). One might also note Raz's (2010) view that we should acknowledge mistakes as our own, in maintaining our sense of competence and self-respect. As Mason notes, this is oddly inward looking: taking responsibility 'is not to do with self-respect, but to do with respecting others in the right way' (2019: 184f).
} 
their stakes in the matter, others may ask or demand that the culprit acknowledge the wrong. A hospital, for example, must reassure patients that it will not accept negligent conduct from its employees, while resisting temptations to sweep failings under the rug or to scapegoat one person for wider problems. Especially where the culprit leaves us in doubt that she really appreciates what those standards require (or more widely, what concern for others requires of her), there will be particular reasons to insist on the wrong. I have left open difficult questions about coercive penalties. But it would be consistent with these remarks to frame them as upholding fair terms of interaction (Ripstein 1999: Chap. 3). So that more careful persons should not be unfairly exposed to risks by those who are not ready to take due care, legal institutions issue authoritative prohibitions. These reach at once forward, to command and deter, as well as backward, to penalise and condemn.

\section{Conclusion}

Negligence highlights a fundamental aspect of human agency: we do and cause things unawares. We may fail to keep track of the world around us-sometimes in ways that are fundamentally incompatible with our adult powers to act and affect others. One view is that even the worst forms of negligence cannot be criminal: we can be culpable only for what we control, not our failures of control; we control our conscious decisions, and only those. But we do not 'control' our decisions: we simply decide, be it reflectively or reflexively. Conscious awareness is neither necessary nor sufficient for control. Deliberate attention may mark someone who is less in control: the learner, or someone facing an unfamiliar (hence especially risky) situation. Deliberate and weak-willed wrongs are failures of control, too.

A full account of culpability has been beyond my scope. But I have suggested that the collective dimensions of non-negligence provide useful clues. The requirements of Thou shalt take care are not delivered by individual reason or good will or explicit instruction. We must take responsibility for judging matters, together. Before we pin blame, we should consider how our collective activities contributed to some harm or near-miss. (I think parallel points apply even to simpler Thou shalt not-s, but that is another story.) Thou shalt take care is not primarily about conscious effort or awareness. We often do more and less and different than we mean to- - and must take responsibility for this, not least by collective activities that enable each of us to act with greater control. (I think parallel points apply to most Thou shalt not-s, though I have only made a few gestures to weak-willed and selfish wrongdoing.) Taking responsibility does not demand mea culpa before every risk that eventuates: our responsibility is bounded by carefully worked-out standards of care. But we must also take responsibility for those standards, not just in the observance but also in the breach. In holding responsible, we take some responsibility for the culprit's agency (perhaps our own). In the happier cases, we contribute to someone's self-understanding and self-control (perhaps our own). In other cases, we take back (some) control. We may affect a person's powers to act in the world, removing trust, exacting compensation, denying authorisations. In the worst cases, criminal proceedings impose their unanswerable condemnation on those who disregard 
even minimal standards of care. In each case, however, I have suggested that we anchor 'culpability' in duties to take responsibility for our agency—our own, and one another's. In our inner lives as in the world we share, control is often a more fallible and fragile achievement than we care to admit. It demands our ongoing care.

Acknowledgements My thanks to Chris Cowley and Beatrice Krebs for the invitation to a workshop on negligence and recklessness (University of Reading, June 2018), and to the audience there. My heartfelt thanks to Chris Cowley for detailed feedback on several drafts, and my gratitude to an anonymous referee for this journal. For further comments and help, many thanks to Marcia Baron, Antony Duff, Lisa Herzog, Morris Kaplan, Myfanwy Williams and Robert Williams.

Funding No external funding was received

\section{Compliance with Ethical Standards}

Conflicts of interest All the authors declare that they have no conflict of interest.

Open Access This article is distributed under the terms of the Creative Commons Attribution 4.0 International License (http://creativecommons.org/licenses/by/4.0/), which permits unrestricted use, distribution, and reproduction in any medium, provided you give appropriate credit to the original author(s) and the source, provide a link to the Creative Commons license, and indicate if changes were made.

\section{References}

Alexander, L. 2000. Insufficient Concern: A Unified Conception of Criminal Culpability. California Law Review 88: 931-954.

Alexander, L \& Ferzan, KK. 2009. Crime and Culpability: A Theory of Criminal Law. Cambridge: Cambridge University Press.

Alexander, L \& Ferzan, KK. 2012. Iconoclasts? Who, Us? A Reply to Dolinko. Criminal Law and Philosophy 6: 281-287.

Alexander, L \& Ferzan, KK. 2018. Reflections on Crime and Culpability: Problems and Puzzles. Cambridge: Cambridge University Press.

Baron, M. 2019. Negligence and the Mens Rea Requirement. Jahrbuch für Recht und Ethik/Annual Review of Law and Ethics 27.

Baron, M. forthcoming. Negligence, Mens Rea, and What We Want the Element of Mens Rea to Provide. Criminal Law and Philosophy.

Cohen, D. 2018. The Inside Story of a Six-year-old Boy's Death, and the Trainee Doctor Who Took the Blame. BBC, https://www.bbc.co.uk/news/resources/idt-sh/the_struck_off_doctor.

Curnow, A. 1996. Death Under Anaesthetic: The Case of Dr Adomako. Medicine, Science and the Law 36: $188-193$.

Dekker, S. 2012. Just Culture: Balancing Safety and Accountability (second edition). Aldershot: Ashgate.

Dixon-Woods, M \& Pronovost, PJ. 2016. Patient Safety and the Problem of Many Hands. BMJ Quality \& Safety 25: 485-488.

Duff, RA. 1990. Intention, Agency and Criminal Liability: Philosophy of Action and the Criminal Law. Wiley-Blackwell.

Duff, RA. 2019. Two Models of Criminal Fault. Criminal Law and Philosophy (early online).

Enoch, D. 2014. Tort Liability and Taking Responsibility. In J Oberdiek (ed.), Philosophical Foundations of the Law of Torts (250-271). Oxford: Oxford University Press.

Feeley, MA. 1979. The Process is the Punishment. New York: Russell Sage Foundation.

Fingarette, H. 2004. Responsibility and Indeterminism, in his Mapping Responsibility. Chicago: Open Court.

Gardner, J. 2003. The Mark of Responsibility. Oxford Journal of Legal Studies 23: 157-171. 
Gardner, J. 2017. The Negligence Standard: Political Not Metaphysical. Modern Law Review 80: 1-21. Helmreich, JS. 2018. Overcoming Luck: Two Trends in Legal Philosophy. Analysis 78: 335-347.

Hieronymi, P. 2014. Reflection and Responsibility. Philosophy and Public Affairs 42: 3-41.

Hieronymi, P. 2019. I'll Bet You Think This Blame Is About You. In DJ Coates \& NA Tognazzini (eds.), Oxford Studies in Agency and Responsibility Volume 5: Themes from the Philosophy of Gary Watson (60-87). New York: Oxford University Press.

Hurd, HM. 2014. Finding No Fault in Negligence. In J Oberdiek (ed.), Philosophical Foundations of the Law of Torts (387-405). Oxford: Oxford University Press.

Johnson, EA. 2010. Is the Idea of Objective Probability Incoherent? Law and Philosophy 29: 419-432.

Keating, GC. 2017. Is There Really No Liability Without Fault?: A Critique of Goldberg \& Zipursky. Fordham Law Review 85: 24-38.

King, M. 2009. The Problem with Negligence. Social Theory and Practice 35: 577-595.

Leipold, AD. 2010. A Case for Criminal Negligence. Law and Philosophy 29: 455-468.

Martin, W. 2009. Ought but Cannot. Proceedings of the Aristotelian Society 109: 103-128.

Mason, E. 2019. Ways to Be Blameworthy: Rightness, Wrongness and Responsibility. Oxford: Oxford University Press.

McGeer, V \& Pettit, P. 2015. The Hard Problem of Responsibility. In D Shoemaker (ed.) Oxford Studies in Agency and Responsibility: Volume 3 (160-188). New York: Oxford University Press.

McGeer, V. 2019. Scaffolding Agency: A Proleptic Account of the Reactive Attitudes. European Journal of Philosophy 27: 301-323.

Moore, MS. 1997. Placing Blame: A Theory of the Criminal Law. Oxford: Oxford University Press.

Moore, MS \& Hurd, HM. 2011. Punishing the Awkward, the Stupid, the Weak, and the Selfish: The Culpability of Negligence. Criminal Law and Philosophy 5: 147-198.

Pronovost, PJ, Goeschel, CA, Olsen, KL, Pham, JC, Miller, MR, Berenholtz, SM, Sexton, JB, et al. 2009. Reducing Health Care Hazards: Lessons from the Commercial Aviation Safety Team. Health Affairs 28: w479-w489.

Provera, B, Montefusco, A \& Canato, A. 2010. A 'No Blame' Approach to Organizational Learning. British Journal of Management 21: 1057-1074.

Railton, P. 2009. Practical Competence and Fluent Agency. In D Sobel \& S Wall (eds.), Reasons for Action (81-115). Cambridge: Cambridge University Press.

Raz, J. 2010. Responsibility and the Negligence Standard. Oxford Journal of Legal Studies 30: 1-18.

Reason, J. 2000. Human Error: Models and Management. British Medical Journal 320 (7237): 768-770.

Ripstein, A. 1999. Equality, Responsibility, and the Law. Cambridge: Cambridge University Press.

Ripstein, A. 2008. Closing the Gap. Theoretical Inquiries in Law 9: 61-95.

Ripstein, A. 2016. Private Wrongs. Cambridge: Harvard University Press.

Rosen, G. 2004. Skepticism About Moral Responsibility. Philosophical Perspectives 18: 295-313.

Sher, G. 2009. Who Knew? Responsibility Without Awareness. New York: Oxford University Press.

Shiffrin, S. 2017. The Moral Neglect of Negligence. In D Sobel, P Vallentyne \& S Wall (eds.) Oxford Studies in Political Philosophy: Vol. 3 (197-228). Oxford: Oxford University Press.

Simester, AP. 2000. Can Negligence be Culpable? In J Horder (ed.), Oxford Essays in Jurisprudence, Fourth Series (85-106). Oxford: Oxford University Press.

Simester, AP. 2013. A Disintegrated Theory of Culpability. In DJ Baker \& J Horder (eds.), The Sanctity of Life and the Criminal Law: The Legacy of Glanville Williams (178-203). Cambridge: Cambridge University Press.

Smith, A. 2005. Responsibility for Attitudes: Activity and Passivity in Mental Life. Ethics 115: 236-271.

Stark, F. 2016. Culpable Carelessness: Recklessness and Negligence in the Criminal Law. Cambridge: Cambridge University Press.

Vargas, M. 2013. Building Better Beings: A Theory of Moral Responsibility. New York: Oxford University Press.

Vargas, M. forthcoming. Negligence and Social Self-Governance. In A Mele (ed.), Surrounding SelfControl. Available at http://vargasphilosophy.com/Papers/NegSSG.pdf.

Waldron, J. 1995. Moments of Carelessness and Massive Loss. In DG Owen (ed.), Philosophical Foundations of Tort Law (387-408). Oxford: Oxford University Press.

Walker, MU. 2006. Moral Repair: Reconstructing Moral Relations After Wrongdoing. Cambridge: Cambridge University Press.

Webber, J. 2009. The Existentialism of Jean-Paul Sartre. New York: Routledge.

Weingarten, G. 2009. Fatal Distraction, Washington Post Magazine, 8 March: 8-27. 
Williams, G. 2017. Verantwortung, Rationalität und Urteil [Responsibility, rationality and judgment]. In L Heidbrink, C Langbehn \& J Sombetzki (eds.), Handbuch Verantwortung (365-393). Wiesbaden: Springer. English version: https://eprints.lancs.ac.uk/id/eprint/86057/7/Williams_2017_Rationalit y_and_Judgment_English_version_1Nov2018.pdf.

Winnicott, DW. 1964. The Child, the Family, and the Outside World. Harmondsworth: Penguin.

Yankah, E (intro./ed.). 2018. 'The Moral Neglect of Negligence' by Seana Valentine Shiffrin. PEA Soup.

May 2. http://peasoup.us/2018/05/the-moral-neglect-of-negligence-by-seana-valentine-shiffrinwith-a-critical-precis-by-ekow-yankah/.

Zimmerman, M. 2009. Responsibility and Awareness. Philosophical Books 50: 248-261.

Publisher's Note Springer Nature remains neutral with regard to jurisdictional claims in published maps and institutional affiliations. 